\title{
The Causal Effects of the Number of Children on Female Employment - Do European Institutional and Gender Conditions Matter?
}

\author{
Anna Baranowska-Rataj ${ }^{1,2}$ (D) Anna Matysiak ${ }^{1,3}$
}

Published online: 19 July 2016

(C) The Author(s) 2016. This article is published with open access at Springerlink.com

\begin{abstract}
This paper contributes to the discussion on the effects of the number of children on female employment in Europe. Most previous research has either (1) compared these effects across countries, assuming an exogeneity of family size; or (2) used methods that dealt with endogeneity of family size, but that focused on single countries. We combine these two approaches by taking a cross-country comparative perspective and applying quasi-experimental methods. We use instrumental variable models, with multiple births as instruments, and the harmonized data from the European Survey on Income and Living Conditions (EU-SILC). We examine the cross-country variation in the effects of family size on maternal employment across groups of European countries with different welfare state regimes. This step gives us an opportunity to investigate whether the revealed crosscountry differences in the magnitude of the effect of the family size on maternal employment can be attributed to the diversity of European institutional arrangements, as well as the cultural and the structural conditions for combining work and family duties.
\end{abstract}

Keywords Family size $\cdot$ Female labour supply $\cdot$ Motherhood penalty $\cdot$ Childbearing

\section{Motivation}

The aim of this paper is to investigate the variation in the magnitude of the effect of the number of children on female employment. This research question attracted considerable

Anna Baranowska-Rataj

anna.baranowska@umu.se

1 Institute of Statistics and Demography, Warsaw School of Economics, Warsaw, Poland

2 Sociology Department, Umeå University, Mediagränd 14, Beteendevetarhuset, 90187 Umeå, SE, Sweden

3 Wittgenstein Centre (IIASA, VID/OEAW, WU), Vienna Institute of Demography / Austrian Academy of Sciences, Vienna, Austria 
interest in the demographic, sociological, and economic literature in the 1980s, and has since been addressed in numerous empirical studies. Previous studies have some methodological shortcomings, however. Many of them employed methods that assumed that childbearing decisions are exogenous with respect to labor market decisions (Matysiak and Vignoli 2008). Thus, these studies failed to account for unobserved characteristics that jointly affect fertility and employment outcomes, such as an unmeasured orientation toward work or family. A failure to account for unobservables leads to a bias in the estimated effect of the family size on women's employment due to the selection of individuals with a high family orientation into the group of the non-employed. Hence, many previous studies have shown associations between family size and female employment instead of causal effects. Some recent studies tried to account for this problem by implementing statistical methods that make it possible to control for unobserved timeconstant characteristics, while assuming that women's orientation toward family or paid work does not change over time (Aassve et al. 2006; Matysiak 2011a). Women's fertility and employment preferences may, however, change in response to the birth of another child or their work experiences. There are only few studies that have succeeded in accounting for both the time-constant and the time-varying unobserved characteristics of women, taking the endogeneity of family size into account. These studies provide evidence for single countries only, which makes it difficult to understand the mediating role of the institutional context for the incompatibility of work and family. Moreover, the variation in the institutional arrangements of these countries is rather limited, as these studies are typically conducted in the U.S. (Rosenzweig and Wolpin 1980; Angrist and Evans 1998; Jacobsen et al. 1999) or in developing countries (Cruces and Galiani 2007; Vere 2011; Cáceres-Delpiano 2012). There is almost no evidence for European countries on the causal effects of family size on women's employment. Hence, the questions of whether, and, if so, how strongly family size affects female labor market outcomes across countries with differential institutional arrangements and cultural and structural conditions have yet to be adequately explored.

In this paper we combine different methodological solutions that provide more indepth insights into how the number of children affects women's employment, and how this effect depends on the country institutional and cultural conditions. First, we take an instrumental variable approach using information on multiple births to compute the causal effects of family size on women's employment. This approach was proposed in the seminal paper by Rosenzweig and Wolpin (1980), and has been applied in a number of recent empirical studies (Cruces and Galiani 2007; Vere 2011; Cáceres-Delpiano 2012). In addition, we use the approach recently proposed by Lewbel (2012) to assess the robustness of our results with respect to the type of instrumental variable. This method allows us to identify the causal effects of family size on women's employment by using regressors that are uncorrelated with the product of heteroskedastic errors. While this approach is generally applied to identify the structural parameters of interest when no instruments are available, in our study it is used to provide overidentifying conditions under which the validity of our instrumental variable based on multiple births can be tested. We examine the variation in the effects of family size on women's employment. We compare the magnitude of the possible effects across European countries, which have a very wide range of institutional, cultural, and structural conditions that may constrain or facilitate combining work and family (Brewster and Rindfuss 2000; Ahn and Mira 2002; Engelhardt et al. 2004). Although most European 
governments claim they are seeking to raise employment levels among women with children, the degree of progress made in implementing these policies differs strongly across countries. Thus, Europe is an interesting laboratory for research on how family policies mediate the impact of childbearing on female employment. Recently, comprehensive micro-data samples from almost all European countries have been collected in the Survey of Income and Living Conditions. The availability of these data make it possible to take advantage of European diversity for research purposes.

Our paper is structured as follows. In Section 2 we provide an overview of theories concerning conflict between work and parenthood. In Section 3 we elaborate on the European institutional and cultural contexts that may moderate the scale of this conflict. In Sections 4 and 5 we describe the data and the methods used in this study. In Section 6 we present the results. In Section 7 we summarize our findings and discuss opportunities for further research.

\section{Literature Review}

The relationship between family size and female employment is very well grounded in existing sociological and economic theories. Sociological theories stress that for a number of cultural and economic reasons, the primary responsibility for childcare continues to lie with the mother (Lehrer and Nerlove 1986). While both paid employment and childcare may be important sources of rewards and satisfaction for women, because of time constraints, women need to decide how to divide their time between working and taking care of their children. This conflict has been described in the role incompatibility hypothesis (Brewster and Rindfuss 2000).

Similar concepts have been developed in the neo-classical economic models of women's labor supply (Mincer and Ofek 1982; Joesch 1994; Rønsen and Sundström 2002). In these models the time that a parent, usually a mother, supplies in the labor market is a choice variable that is jointly determined with the time devoted to childrearing. A parent will take a job only if her or his market wage exceeds the value of the time spent at home (a reservation wage). According to this model, the impact of family size on parental involvement in the labor market can be positive, as having children increases the financial needs of the family (income effect); but it can be also negative if the income effect is surpassed by an increase in the value of a parent's time spent at home following the birth of a child (price effect).

According to economic theory, the effects of family size on employment are more likely to be negative for women with a low earning potential, a strong desire to spend time with children, and a low orientation toward paid work; as well as for women living in an affluent household. The effect of family size on women's employment should also depend on the country context. The value of women's time is expected to be higher in countries where working mothers are less institutionally supported (e.g., countries with poor childcare provision or inflexible working hours) or less socially accepted (Gornick et al. 1997; EspingAndersen 1999; Stier et al. 2001). In such countries, working is more costly for a mother, as she needs to purchase childcare on the market and violate the prevalent gender norms.

The abundant empirical research on the topic has confirmed that having children exerts a negative influence on women's employment (Felmlee 1993; Giannelli 1996; Taniguchi and Rosenfeld 2002; Budig 2003). This evidence comes mainly from single-country 
studies or studies that compared two or three countries. There are fewer multi-national studies that would allow us to draw conclusions about the magnitude of the effect across country contexts (Steiber and Haas 2012). One of the few multi-national studies that have been carried out is by Pettit and Hook (2005), who used cross-sectional data on 19 European countries and compared the employment rates of childless women with those of women in households with small children. Their findings suggest that having young children affects women's employment significantly less in countries that provide public childcare and parental leave, and that national gender cultures do not explain the crossnational differences in women's employment. Similar conclusions have been reached by Steiber and Haas (2012) (2012) for 26 countries and by Uunk et al. (2005) for 13 European countries. Finally, using data for 18 OECD countries, Nieuwenhuis et al. (2012) demonstrated that the cross-country differences in the effects of parenthood on women's employment are attributable not just to family policies, but also to labor market structures (unemployment rates and the size of the service sector).

The comparative studies mentioned above all provide information about associations between family size and women's employment across Europe. However, they do not account for the selection of family-oriented women into motherhood and nonemployment due to unobserved time-varying - and, in the case of some of these studies, also time-constant — characteristics of women. As the literature has shown that women who are more career-oriented generally prefer to have smaller families (Lehrer and Nerlove 1986; Francesconi 2002; Hakim 2003), the findings of these studies cannot be interpreted in terms of the effects of family size on women's labor market outcomes.

There are only a small number of studies that control for endogeneity of family size, and most of those that exist are limited to one country only (Rosenzweig and Wolpin 1980; Angrist and Evans 1998; Jacobsen et al. 1999; Vere 2011), or they compare developing countries only (Cruces and Galiani 2007; Cáceres-Delpiano 2012). Notable exceptions are the studies by Del Boca et al. (2009) and Del Boca and Sauer (2009), who provided cross-country comparative evidence on the role of institutional arrangements for employment and fertility decisions in western Europe. However, they did not show the effects of family size on employment, and instead focused on the effects of policies on employment and fertility. Hence, there is very little evidence on the moderating effects of the country context on women's employment that is not potentially biased by selection.

\section{European Context}

Across European countries, there is considerable diversity in the conditions for work and family reconciliation. These conditions are shaped by family policies, labor market regulations, and gender norms. Not surprisingly, there have been many attempts to classify countries according to the extent to which they provide the conditions needed to combine work and family (Anttonen and Sipilä 1996; Gornick et al. 1997; EspingAndersen 1999; Korpi 2000; Bettio and Plantenga 2004). Although these classifications differ in how they assign various countries to specific family policy and attitudinal models, there is general agreement that the most favorable conditions for combining paid work with childrearing are in Nordic Europe. These countries stand out for their 
exceptionally well-developed childcare services, which are characterized by their very high coverage rates for the youngest children (under age 3), their relatively high coverage rates for pre-school children, and their relatively long opening hours (see Table 1). These countries were also forerunners in introducing the individualized right to parental leave to encourage fathers to become more involved in care (Leira 2002). In the Nordic countries, mothers' employment is also highly socially accepted (Treas and Widmer 2000). The Gender Norms Index developed by Matysiak and WeziakBialowolska (2016) on a battery of attitudinal statements on gender norms from the European Value Survey (2016) suggests that these countries score far higher than the other European countries in terms of the social acceptance of women's participation in the public sphere and fathers' participation in the private sphere (see Table 1). The southern European countries lie on the other side of the spectrum. In these countries, there is very limited institutional support for working parents in terms of public childcare provision, particularly for the youngest children; parental leave entitlements are short and very poorly paid; and very conservative attitudes toward women's involvement in any public sphere of life, including labor market attachment, are prevalent (see Table 1, but also Matysiak 2011a; Matysiak and Weziak-Bialowolska 2016; Lück and Hofäcker 2003). Surprisingly, individualized rights to parental leave benefits were introduced quite early in this group of countries as well. Currently, however, only around $10 \%$ of fathers in southern Europe use these benefits, compared to $50 \%$ in Sweden (European Commission 2015).

The conditions for work and family reconciliation in other parts of Europe are more nuanced. In Belgium and France, the public provision of childcare services is nearly as good as in the Nordic countries, but the costs of childcare for families are higher (see Table 1). The policies in those countries are strongly targeted at increasing women's employment and easing women's care responsibilities, but they are less geared toward encouraging egalitarian division of labor at home. In Belgium and France, paternity leave entitlements have been introduced only recently, and the prevailing attitudes toward working mothers are more traditional (Table 1). Austria and Germany score even lower in terms of their support for working mothers. Indeed, in these two countries mothers have long been encouraged to stay at home to care for their children by the family benefit and parental leave policies and by the joint tax system (Steiner and Wrohlich 2004). In the Netherlands, in contrast, parents have been given very limited access to leave. Yet despite some recent changes in work-family reconciliation policies, childcare provision in the German-speaking countries and in the Netherlands has remained poor, particularly for children under age three. Moreover, because the opening hours of childcare facilities in these countries are among the shortest in Europe (Table 1), mothers are often forced into part-time employment. Finally, levels of social acceptance of mothers' involvement in the labor market and fathers' involvement in the family are even lower in these countries than they are in Belgium and France (Table 1).

The Anglo-Saxon countries constitute another specific group of countries. In this country group the cultural barriers to female work are not as strong as in the Germanspeaking countries and the Netherlands (Table 1), but levels of public support for working parents are far lower. The parental leave systems in these countries are very modest, with very low payments during leave. Public childcare provision also tends to be rather poor. Although childcare services can be easily purchased on the market, the cost of these services for the parents is usually high. As a result, the coverage rates in 
Table 1 A summary of the differences between the country groups with regard to the family policies and gender norms, 2004-2012

\begin{tabular}{|c|c|c|c|c|c|c|}
\hline & Nordic & Western-French & Other Western & Anglo-Saxon & Southern & CEE \\
\hline $\begin{array}{l}\text { Childcare fees per 2-year-old } \\
\text { in } \% \text { of average wage, } 2004^{\mathrm{a}}\end{array}$ & 8.3 & 22.4 & 17.1 & 24.7 & 20.8 & 7.0 \\
\hline $\begin{array}{l}\text { Public spending on childcare } \\
\text { and pre-primary education } \\
\left(\% \text { GDP), } 2007^{\ddagger}\right.\end{array}$ & 1.0 & 0.9 & 0.4 & 0.7 & 0.4 & 0.5 \\
\hline $\begin{array}{l}\text { Individual entitlement to } \\
\text { childcare services for } \\
\text { children under } \\
2 \text { years old, } 2009^{\dagger}\end{array}$ & Yes $^{*}$ & No & No & No & No & No \\
\hline $\begin{array}{l}\text { Coverage rate for children } \\
\text { under } 3 \text { years old, } 2004^{\dagger}\end{array}$ & 41.0 & 38.6 & 11.9 & 20.5 & 13.5 & 13.7 \\
\hline $\begin{array}{l}\text { Coverage rate for } \\
\text { 3-5-year-olds, } 2004^{\dagger}\end{array}$ & 87.8 & 99.5 & 87.8 & 85.0 & 81 & 75.2 \\
\hline $\begin{array}{l}\text { Average hours in formal care } \\
\text { during a usual week for } \\
\text { 0-2-year-olds, } 2013^{*}\end{array}$ & 33.6 & 31.8 & 25.4 & 21.8 & 32.0 & 34.5 \\
\hline $\begin{array}{l}\text { Duration of paid parental } \\
\text { leave multiplied } \\
\text { by the income replacement } \\
\text { rate of the parental leave } \\
\text { benefit (in months), } 2009^{\dagger}\end{array}$ & 11.5 & 8.8 & 10.0 & 3.2 & 4.6 & 16.1 \\
\hline $\begin{array}{l}\text { Gender Norms Index } \\
\text { (Matysiak and Weziak- } \\
\text { Bialowolska 2016), 2008 }\end{array}$ & 86.1 & 64.6 & 48.5 & 60.6 & 35.8 & 41.5 \\
\hline
\end{tabular}

Nordic countries (Denmark, Finland, Island, Norway and Sweden), western-French (Belgium and France), other western (Austria, Germany, Luxembourg and the Netherlands), Anglo-Saxon countries (UK and Ireland), southern European countries (Spain, Italy, Portugal and Greece) and central and eastern European countries (Czech Republic, Hungary, Poland, Slovakia, Romania, Bulgaria, Slovenia, Estonia, Latvia and Lithuania). Sources: ${ }^{\dagger}$ Multilinks Database on Intergenerational Policies, ${ }^{\star}$ OECD Family Database, ${ }^{¥}$ index developed by Matysiak and Weziak-Bialowolska (2016) on the data from European Value Survey (2016); it ranges from 0 - traditional to 100 - egalitarian

the childcare system are relatively low, and the childcare fees are the highest in Europe. However, in these countries the labor market is relatively flexible; i.e., while it is easy to lose a job, it is also relatively easy to find a new one (Adsera 2005).

Finally, the specificity of central and eastern Europe (CEE) is related to the legacy of state socialism. During the socialist era, women were expected to be both income and care providers (Pascall and Manning 2000), and the state provided extensive childcare services in the form of either free childcare facilities or crèches and kindergartens attached to state-owned enterprises. After the economic transition, public expenditures on reconciliation policies were greatly reduced and most of the state-owned enterprises went bankrupt or were privatized. Only some of the CEE countries attempted to rebuild the welfare support for working parents in the 2000s. As a result, family policy models in this part of Europe have become increasingly diverse, with Slovenia and Estonia offering the most generous support to working mothers; while the Czech Republic, Slovakia, and Poland pursue familialism (Szelewa and Polakowski 2008; Matysiak 
2011a). On average, however, the enrollment rates in crèches and kindergartens in the CEE region are among the lowest in Europe. Instead of investing in childcare provision, these governments continue to offer quite generous parenatal leave schemes (in terms of length and payment), which allow women to withdraw from employment during the first three years of a child's life. Interestingly, women tend to return to employment after this leave period (Matysiak 2011b), and usually take full-time jobs (Drobnič 1997). This pattern, which is very specific for the region, is partly the result of conflicting social expectations of women. On the one hand, women in the region are perceived as the main care providers, and childcare and housework are seen as female, not male jobs. On the other hand, women are also expected to work in the market and to contribute to the usually tight household budget (Lück and Hofäcker 2003; Philipov 2008).

\section{Data and Methods}

\section{Analytical Strategy}

As it has been noted in Section 2, a mother's decision about whether to be employed depends on her preferences regarding paid work, desire to spend time with her children, the financial situation of her household, the earning potential of her partner, and her own earning capacities. This implies that we would need to control for all these variables in order to properly estimate the effect of family size on a mother's employment. In practice, controlling for all of these variables is usually impossible, as researchers generally lack the necessary data to do so. In particular, we are not able to observe women's orientations toward paid work and family. A number of theoretical and empirical studies have suggested that women with a comparative advantage in market work display a stronger preference to have small families (Lehrer and Nerlove 1986; Francesconi 2002; Hakim 2003). If this is the case, then research that ignores the role of female preferences and treats family size as exogenous may overestimate the negative effects of childbearing on the labor market outcomes of mothers.

Furthermore, various unobserved characteristics such as earning potential and tastes for paid work, childcare and leisure may vary across various life phases. Specifically, the presence of children in the family significantly affects female preferences for these three types of activities (Joshi 1998; Blau and Kahn 2007). Hence, after each birthand especially after the first birth that marks the transition to parenthood-individual preferences may change. This means that even sophisticated methods of analysis that control for the unobserved time-constant characteristics of women might still generate misleading conclusions.

An experimental setting in which women could be randomly sorted into various "treatment groups" with an exogenously defined number of children would be ideal for addressing this research problem. For obvious reasons, organizing such an experiment is not possible. However, Rosenzweig and Wolpin (1980) have proposed a method for exploiting an experiment that occurs naturally due to the occurrence of multiple births. The basic idea is to use the data on multiple births in order to construct a proper "control group" for women with a given number of children. Women who experienced multiple births may be regarded as a random "sample" that may be used for 
comparisons with women who experienced births of singletons. Thus, information on twin births can be applied to construct an instrumental variable and to get unbiased estimates of the impact of the number of children on women's employment. For example, women who have had just one child can be compared to women who have had two children as the result of a multiple birth.

The instrumental variable approach exploiting information on twin births is regarded as comparable to a natural experiment; it gives us the opportunity to control for the simultaneity of family size and employment decisions among mothers without making any specific assumptions about the distribution or temporal stability of the unobserved factors that jointly affect women's family-related and employment-related decisions (Moffitt 2005). The estimates from instrumental variable models refer only to the subsample of the population who react to the instrument; i.e., the compliers (Angrist et al. 1996). In the presence of heterogeneous treatment effects, these estimates may differ from those of the average treatment effect and the average treatment effect for the treated. However, the specific feature of the instrumental variable that we use in this paper is that it identifies the effect of treatment on the non-treated, since compliance is perfect when a multiple birth occurs (Angrist et al. 2010). Still, this variable does have some drawbacks. First, it does not allow us to measure the effect of the first child on female labor supply. Using this approach gives us the opportunity to measure the family size effects at parity two or higher. Second, the occurrence of multiple births correlates with some demographic variables, such as a mother's age at birth or her race (Martin and Park 1999, see also the results of our analysis presented in Appendix Table 9). These demographic information are, however, often available in the data, and can be controlled for in regression models. ${ }^{1}$ Another potential problem is that raising children born in multiple births may affect labor market outcomes differently than raising children from single births, and this difference may depend on the age of the children. Taking care of newborn twins can be more time-intensive than taking care of one newborn and his or her older brother or sister. At older ages, however, economies of scale may reduce the amount of time parents have to invest in taking care of twins than in taking care of two children who are of different ages. For example, since twins often attend the same classes, parents may need to spend less time on helping twins with their homework than children of different ages (Rosenzweig and Zhang 2009).

Obviously, the instrumental variable approach used in our paper is not the only possible solution. For example, previous research has exploited idiosyncratic changes in policies that increased the availability of family planning programs in the community as sources of exogenous variation in childbearing (Arpino and Aassve 2013). However, this approach allows us to measure the family size effects in selected countries only; namely, in those countries where cross-regional variation in access to contraceptives can be observed empirically. Other studies have exploited data on miscarriages and the presence of infertility problems. Some miscarriages occur at random due to the formation of abnormal fetal chromosomes at the time of conception, which causes fetal expulsion early in a

\footnotetext{
${ }^{1}$ Previous research has shown that, historically, multiple births have been substantially more common among mothers of African-American origin than among mothers of other race groups (Luke and Martin 2004). The way we controlled for racial background is imperfect because we only have information about whether a mother was born in an EU country.
} 
pregnancy (Hotz et al. 1997; Hotz et al. 2005). However, epidemiological studies have found that the incidence of miscarriages is also higher due to the consumption of cigarettes and alcohol during pregnancy (Kline et al. 1980). At the same time, smoking cigarettes and drinking alcohol are correlated with labor market outcomes (Bray 2005; Johansson et al. 2007; Levine et al. 1997). This undermines the internal validity of the instrument based on miscarriage data. Infertility, another possible instrument, can be defined as the failure to conceive after a year of regular intercourse without contraception (Habbema et al. 2004). Studies in which instruments based on infertility have been applied include Agüero and Marks $(2008,2011)$ and Cristia (2008). Unfortunately, a wide range of factors - such as poor health, smoking, drinking, and extreme body mass index - are associated with infertility, and may depress labor market chances.

Another type of instrumental variable that gives us the opportunity to study the family size effects on labor market outcomes is the siblings' gender composition. There is evidence of a preference for "balanced" families with equal numbers of boys and girls in some countries. Therefore, some studies have used the gender composition of children as an instrument for family size (Angrist and Evans 1998; Cruces and Galiani 2007; Daouli et al. 2009; Nam 2010). The internal validity of the instrumental variable constructed based on information about siblings' gender composition is also under debate (Rosenzweig and Wolpin 2000). Moreover, in many countries the impact of sex composition on the total number of children is not always strong enough to serve as a relevant instrument for family size. Finally, this approach is not practical for use in a study that focuses on Europe, because it provides estimates of the effect of having an additional child on female labor force participation that are conditional on reaching parity two, whereas the numbers of women with at least two children are very small in many European countries (Del Boca and Sauer 2009). ${ }^{2}$

In this study, we cannot use the instrumental variables based on miscarriages or infertility because the relevant information is not available in our data. We examined the opportunity of using an instrumental variable based on gender composition, but our results showed that having two children of the same gender has a very small impact on the total number of children, and the tests of the relevance of gender indicated that this instrument is very weak. ${ }^{3}$ In lieu of using additional instruments, an additional strategy that we followed in order to assess the robustness of our results is the approach proposed recently by Lewbel (2012). This method relies on the presence of heteroscedasticity in the error term of the first-stage equation (which is examined in this paper by means of the Breusch-Pagan test). The procedure suggested by Lewbel (2012) uses as instruments the deviations from the mean of a vector of independent exogenous variables, interacted with the residual from the first-stage regression. Previous research has applied this approach to identify the key parameters of interest in cases in which the instrumental variable was not available (Kelly et al. 2014), or to provide over-identifying conditions

\footnotetext{
2 This is important because in the presence of heterogeneous treatment effects, the local average treatment effect identified by means of an instrumental variable model may differ from the average treatment effect when individuals influenced by the instrument (e.g., mothers with at least two children of the same gender making the decision to have another child) are not representative of the overall population.

${ }^{3}$ Specifically, according to our calculations carried out for the last available wave of EU-SILC dataset, having children of the same gender among parents with at least two children increases family size by less than 0.1 of a child. The F-statistic computed for this instrumental variable varies between 1.14 and 6.38, indicating a weak instrument problem in all of the country groups (Staiger and Stock 1997).
} 
under which the validity of the main instrumental variable could be tested (Sabia 2007). In this paper we use this approach for the latter purpose.

\section{Data}

So far, there have been relatively few studies that have employed the instrumental variable models using data on multiple births because of the lack of a dataset with sufficiently large samples and detailed demographic information. In this study we are fortunate to have access to the European Survey of Income and Living Conditions (EUSILC), which includes large samples, and thus allows us to identify a suitable number of mothers who experienced multiple births (Eurostat 2011). ${ }^{4}$ Additionally, the survey provides data on the labor market situations of the respondents and the structure of their families. It was started in 2004 and has been carried out every year under the auspices of Eurostat. It provides harmonized comparable data for most countries in Europe. Based on these data, cumulated from the period 2004-2011, we can analyze and compare the effect of childbearing on employment among mothers in 30 European countries (all of the members of the European Union and Norway, Iceland, and Switzerland).

We restricted our sample to mothers aged 18-35 whose oldest child was under age 12. We excluded from our analysis women for whom the relevant information on the labor market outcomes was missing. We identified women who gave birth to two children in the same year and in the same quarter as being mothers of twins. For countries in which the information on the quarter of birth was missing, we used only the data on the year of childbirth in identifying mothers of twins; and we controlled for this fact in our analyses. As there were very few women who gave birth to triplets or experienced other types of multiple births, we excluded such cases from the analysis. We used all of the national EUSILC samples apart from samples from surveys carried out in Malta, Cyprus, and Switzerland. These countries lack descriptions of the institutional and the cultural settings relevant to our analysis, and Switzerland has only recently been included in the survey. The total number of mothers who experienced a twin birth as their first birth is 1719 . The twinning probability is 1.27 , which is in line with the existing literature on multiple births (Martin and Park 1999). The sample used in the analysis includes 135,340 mothers.

We focus on two measures of women's labor market involvement: the probability of doing work, which captures the extensive margin of female labor market involvement; and the number of hours worked, which captures the intensive margin. The probability of doing paid work is defined based on the information on the current economic activity status, which distinguishes between (1) working full-time, (2) working part-time, (3) unemployment, (4) studying, (5) retirement, (6) disability, (7) compulsory military service, (8) fulfilling domestic and care responsibilities, and (9) other forms of inactivity. We classified the first two categories as involvement in work, whereas the other labor market statuses were classified as being out of work. The EU-SILC also provides information on the number of hours usually worked per week in the main job among working women. For women who were not working we assumed zero hours of work; thus, this outcome variable is not conditional on women's labor market status.

We pooled the data for all countries in order to investigate the variation in the effects of having children on mothers' employment between groups of countries that have similar

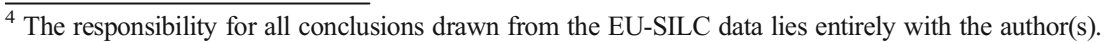


institutional, cultural, and structural conditions for work and family reconciliation. The country groups were specified according to the commonly applied classification of welfare state regimes described in Section 3. The first group consists of the Nordic countries (Denmark, Finland, Island, Norway, and Sweden); the second category includes Belgium and France; the third group consists of Austria, Germany, Luxembourg, and the Netherlands; and the fourth group is made up of Anglo-Saxon countries (UK and Ireland). Finally, the last two groups cover the southern European countries (Spain, Italy, Portugal, and Greece) and the central and eastern European countries (Czech Republic, Hungary, Poland, Slovakia, Romania, Bulgaria, Slovenia, Estonia, Latvia, and Lithuania).

\section{Model Specification}

In principle, if the randomization of women with children was perfect, we could simply compare the employment rates of women with singletons and women with twins. However, to address the problems of the relationship between the risk of multiple births and age and to improve the precision of our estimates, we use two stage least squares (2SLS) instrumental variable models. In the regression framework, we can control for the individual-level characteristics of women as well as cross-country variation in the institutional setup and cultural conditions. We can also see whether the country-specific institutional or cultural factors moderate the impact of family size on female employment by introducing interaction terms implemented in line with Wooldridge's (2010) suggestion.

We chose the following specification of the 2SLS instrumental variable models, which allows for:

$$
\begin{gathered}
\text { nchild }=\alpha_{0}+\alpha_{1} \text { multi }+\alpha_{2} X+\alpha_{3} \text { countrygroup }+\varepsilon_{1} \\
\text { work }=\beta_{0}+\beta_{1} \text { - } \text { nchild }^{\text {- }}+\beta_{2} X+\varepsilon_{2}
\end{gathered}
$$

where nchild is the total number of children, multi is an indicator that a given woman has experienced a multiple birth, $X$ is a vector of control variables that includes age and age at first birth, as well as country-wave fixed effects. To see if there is variation in the causal effects of family size on maternal employment across the specific groups of European countries, we divided the European countries into groups that - as described in Section 3-have similar institutional settings, and we ran the regression models across different country groups.

In order to test the validity of the instruments based on multiple births, we generated additional instrumental variables by means of the Lewbel (2012) method. In the presence of heteroskedastic disturbances in the first stage equation of the instrumental variable model, the parameters of the second stage equation can be consistently estimated using an exclusion restriction in the form:

$$
(Z-Z) \varepsilon_{1}
$$

where $\mathrm{Z}$ is a vector of exogenous variables (in our paper these are age as well as a set of fixed effects for country groups) and $\hat{\varepsilon}_{1}$ are the estimated residuals from the first stage equation. Next, due to the use of these additional instrumental variables, the second 
stage regression becomes over-identified, and we can thus perform a test of the validity of the multiple birth instrumental variable. Specifically, we examined the difference between the Sargan statistic of the equation and the set of instruments generated by means of Lewbel's (2012) approach and the equation that additionally includes the instrument based on multiple births.

\section{Empirical Results}

\section{Descriptive Statistics}

In order to provide some preliminary insights into the impact of the number of children on female labor market attachment, we present the maternal employment rates (Fig. 1) and the number of working hours among mothers (Fig. 2) by the number of children under age 12, as calculated based on EU-SILC data. In general, the number of children is clearly negatively associated with employment opportunities among European mothers. Having two children instead of one is associated with a difference in employment rates of 17 percentage points. Having a family with three children decreases employment rates by 32 percentage points. Among mothers with four children or more, employment rates are close to zero.

These effects vary very strongly depending on the country group, however. As we can see on Fig. 1, in the Nordic countries the employment rates of mothers vary little depending on whether they have one child or two children; only having three or more children is related to a strong decrease in employment rates in these countries. In the French-speaking western European countries, the difference in the employment rates of mothers depending on whether they have one or two children is also smaller than it is in the rest of Europe, but it is larger than in the Nordic countries. In other western European countries, the gap in the employment rates of mothers depending on their number of children is larger. However, it is evident that the strongest penalty for having more than one child can be observed in the Anglo-Saxon countries, the southern European countries, and the CEE countries. In these countries, having a second child is associated with a decrease in employment rates of about 20-30 percentage points, and having more than two children lowers the probability of having a job to close to zero.

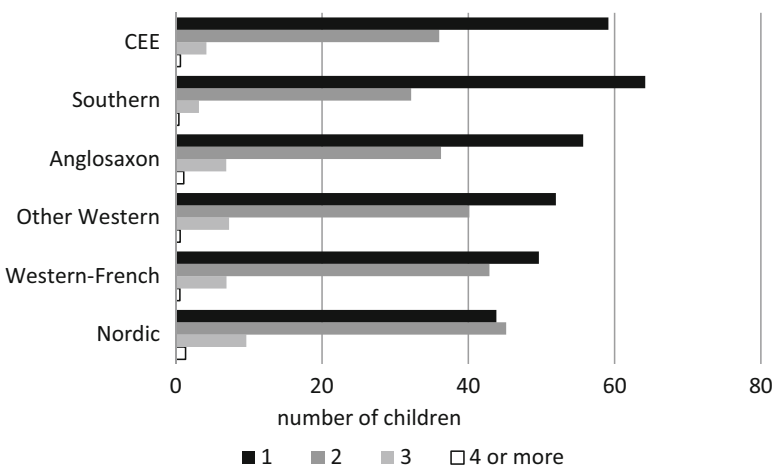

Fig. 1 Maternal employment rates by number of children. Source: EU-SILC data, 2004-2011 


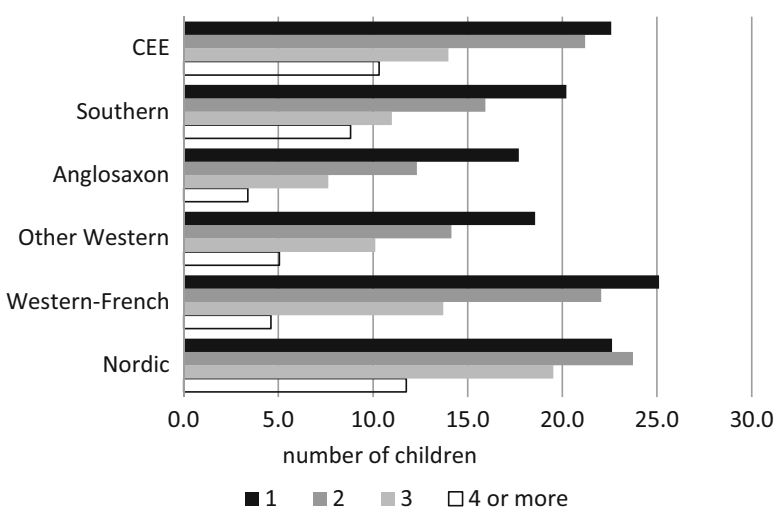

Fig. 2 Number of hours worked by mothers by number of children. Source: EU-SILC data, 2004-2011

While the aggregate employment rates capture how the likelihood of having a job is affected by family size, an indicator of the number of hours worked shows the intensity of labor market involvement. Some women may respond to the increase in the workfamily conflict after the birth of the second child by reducing the amount of time they work rather than by simply withdrawing from the labor market. Again, the gaps in the numbers of hours worked by mothers based on their number of children vary strongly across countries. In the Nordic countries women with two children work one hour longer on average than women with one child, and a decrease in the number of working hours can only be seen among women with at least three children, but even then it is modest relative to that of the other European countries. The negative effects of the number of children tend to be strong in Western Europe, especially in the Frenchspeaking and the Anglo-Saxon countries. In the countries of southern Europe and central and eastern Europe the gap in the number of hours worked by mothers with different numbers of children is rather modest. This finding is consistent with previous research showing that women's part-time employment in those regions, particularly in CEE countries, is not very common (Matysiak and Steinmetz 2008).

\section{Country Group Analysis}

The above descriptive analysis shows associations rather than genuine relationships between family size and female labor supply. Obviously, women select into groups of mothers with different numbers of children based on a number of factors, which may simultaneously affect employment opportunities. In the next step, we carry out regression analysis in order to see how the effect of the number of children varies across countries after we eliminate the selection effect of the observed and the unobserved characteristics of mothers by means of a 2SLS procedure.

We first present the means of the explanatory variables and the results from the first stage of our regression in Tables 2 and 3, respectively. The results in Table 3 indicate that the number of children is larger among older women, and that it negatively correlates with the age at first birth, which confirms the well documented effect of the postponement of childbearing on the level of completed fertility (Sobotka 2004). The effect of twins at first birth on the number of children is close to 0.7 and the F statistic exceeds by far the level of 10, meaning that the twinning variable is not a weak instrument. 
In Tables 4 and 5 we report the results from an IV regression in which we "randomized" women according to their number of children by using data on twin births. In order to see how the effect differs depending on whether we control for the unobserved characteristics of women, as a "baseline" we also report results from an ordinary OLS regression, which has an identical specification but does not imply a quasi-experimental design.

The OLS results show a decline in the probability of working with an increase in the number of children in all groups of countries. According to the results of the IV regression, this effect is neither significant in the Nordic countries nor in CEE countries. However, the results of the OLS regression and the IV models are similar in other country groups and there are no substantial differences in the effects of the number of children on mothers' employment across these remaining country groups. According to the results of the IV models, an increase in the number of children has a somewhat stronger negative effect on mothers' employment in southern Europe and in the Anglo-Saxon countries (where one additional child decreases the probability of working by about $20 \%$ ) than in western Europe (where a corresponding effect amounts to slightly over $10 \%$ ).

The results illustrating the effects of family size on the number of working hours are similar. An increase in family size leads to a decline in working time of about 5-8 h weekly. This effect is weaker in the IV regression than in the OLS regression in the Nordic and the CEE countries, where it also ceases to be significant. The differences between the results of these two models in the Nordic and the CEE countries suggest that a strong preference for larger number of children leads to a reduction in women's working hours in these two groups of countries. Hence, we can observe a selection of strongly familyoriented women into the non-employed group. At the same time, we find no evidence that family size has a causal effect on women's labor supply in these two groups of countries.

\section{Sensitivity Analyses}

In order to assess the robustness of our results, we used a strategy proposed by Lewbel (2012) to exploit heteroscedasticity in the first stage equation in order to generate additional instruments, which may augment our model so that the parameters become overidentified. As a result, we can perform the tests of the validity of the instrumental variable based on twin births. We carried out this sensitivity analysis separately for every country group, and present the results in Tables 6 and 7. In the first step, we

Table 2 Sample means and proportions

\begin{tabular}{lccccrr}
\hline & Nordic & Western-French & Other Western & Anglo-Saxon & Southern & CEE \\
\hline Paid work & 67.2 & 58.0 & 51.2 & 51.7 & 54.9 & 67.2 \\
Hours of work & 22.6 & 22.2 & 15.6 & 14.1 & 18.1 & 21.4 \\
Number of children & 1.8 & 1.7 & 1.7 & 1.8 & 1.5 & 1.6 \\
Age & 30.9 & 30.8 & 31.0 & 29.9 & 31.1 & 30.2 \\
Age at 1st birth & 25.8 & 25.8 & 12.1 & 10.4 & 24.2 & 13.6 \\
Non-EU origin & 7.9 & 10.9 & & & 23.6 \\
\hline
\end{tabular}

Source: EU-SILC data 2004-2011 


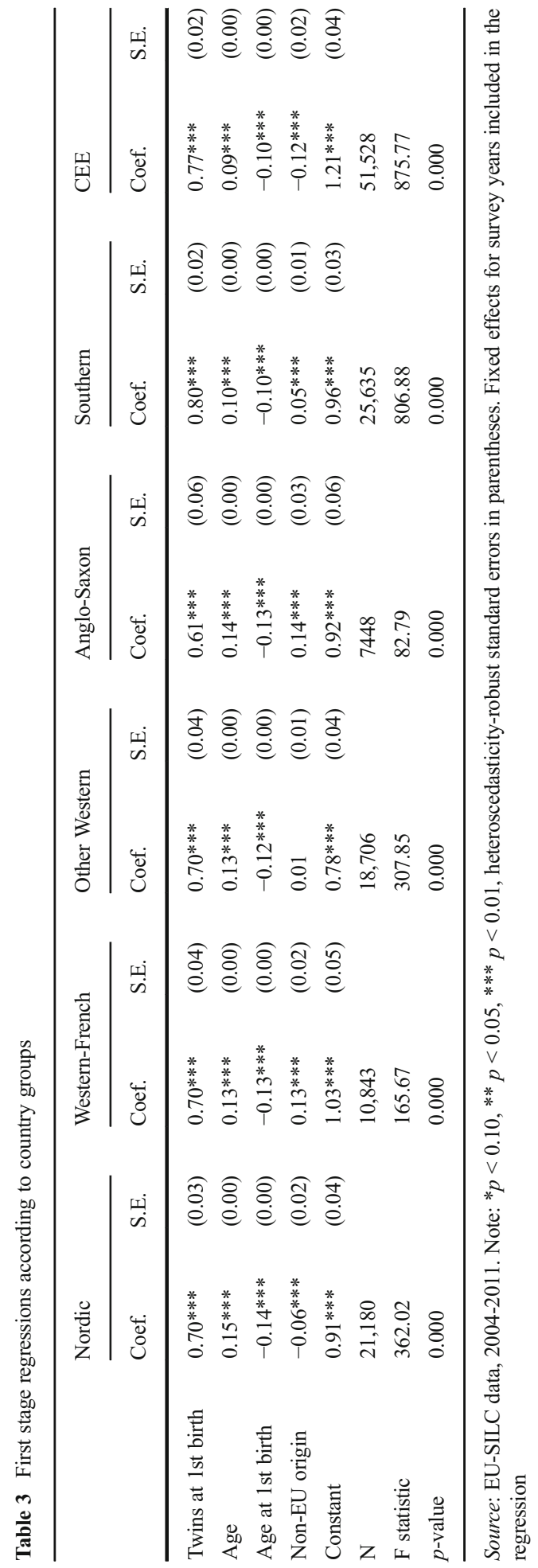




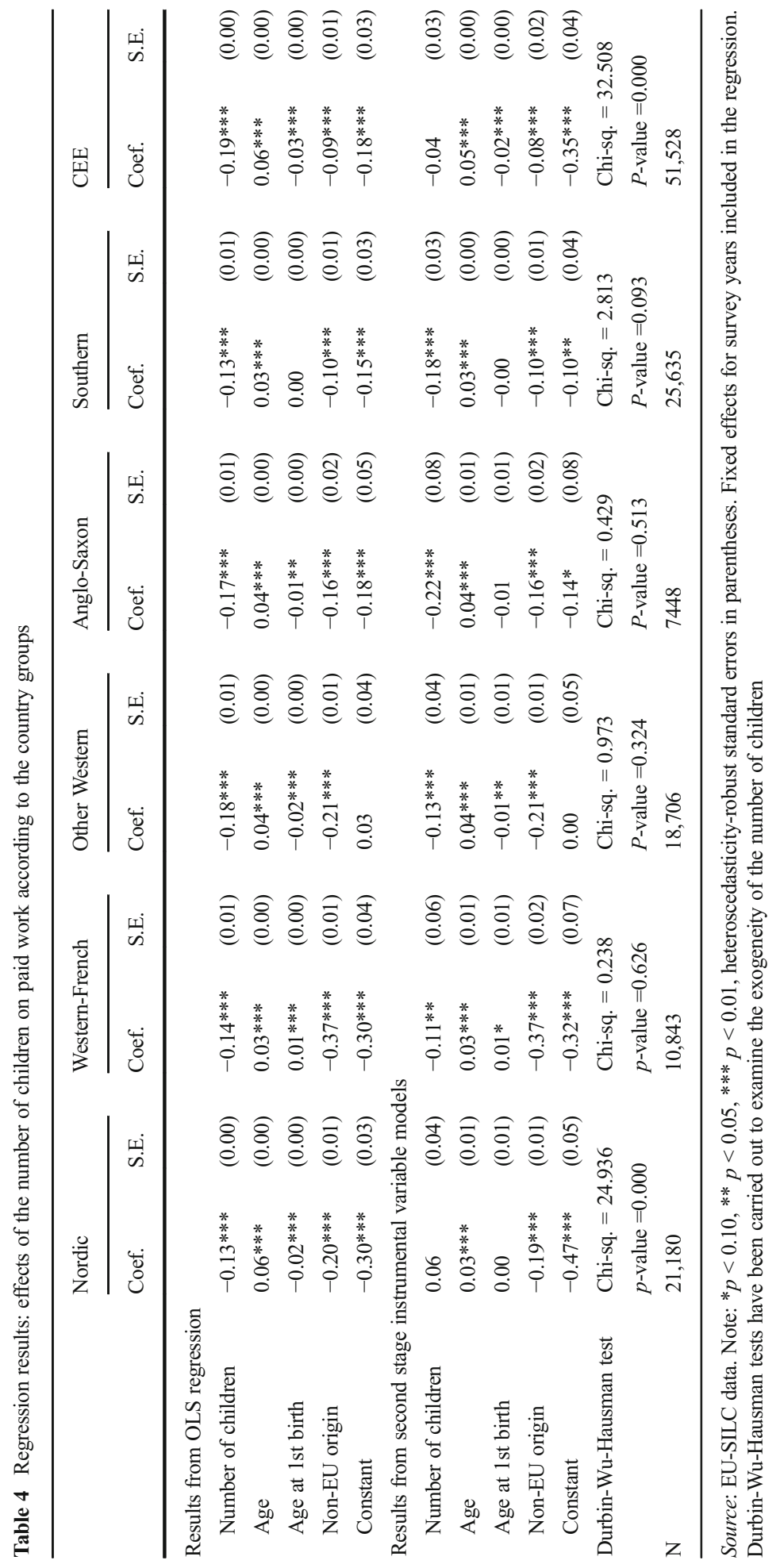




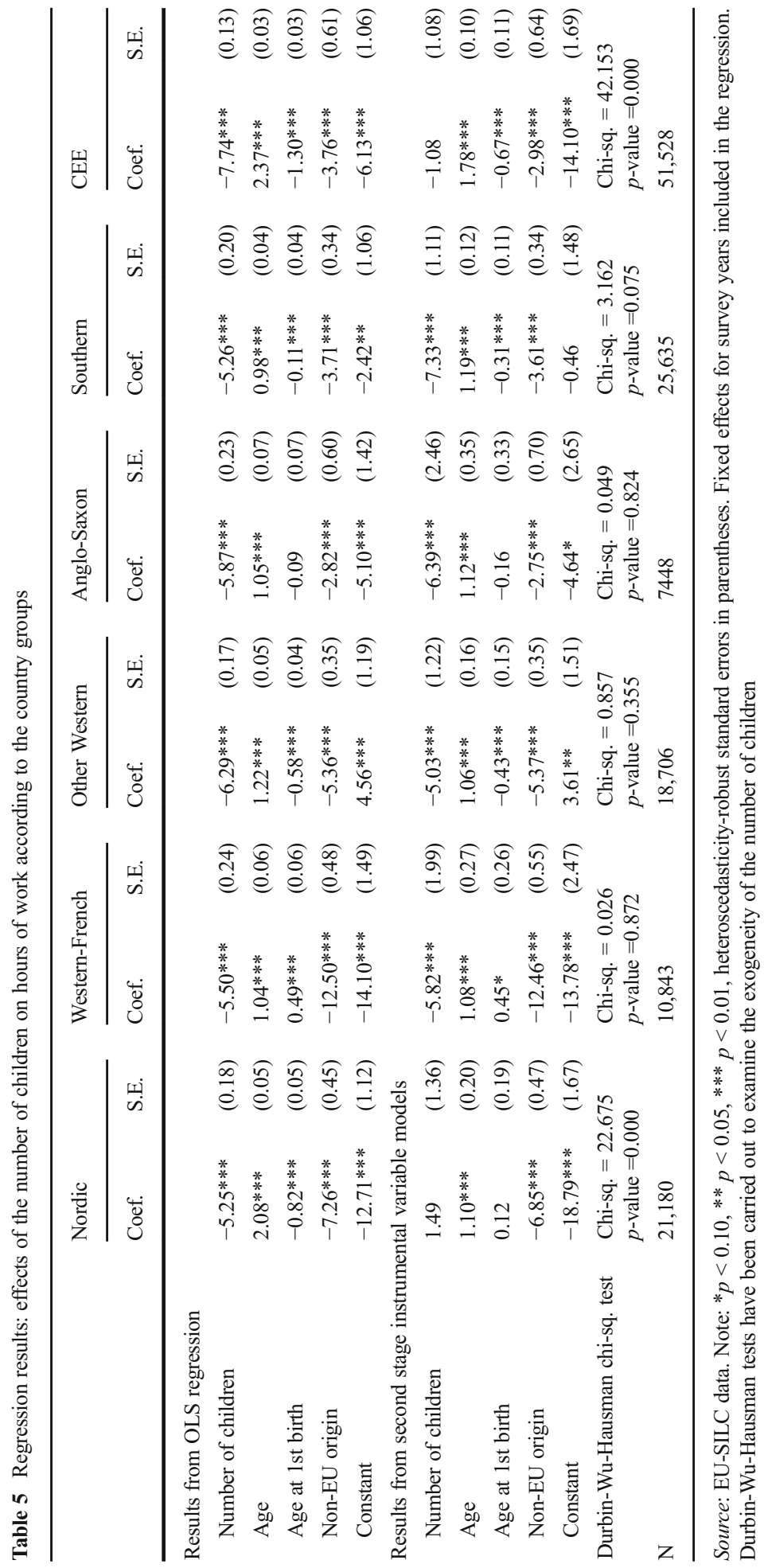


carried out the Brausch-Pagan test, which revealed the presence of heteroscedasticity in the regression for every country group. The availability of heteroskedastic residuals was a precondition for the next step; i.e., for generating additional instrumental variables that are calculated as the product of the first stage equations' residuals and the exogenous variables in mean-centered form. We compared the results from the models estimated by using Lewbel's (2012) approach, and by combining the heteroskedascity-based instrumental variables and the twin-based instrumental variable, we carried out Sargan tests of the validity of the instrumental variable based on twin births. Under the null hypothesis of validity, the change in the Sargan statistic follows a chi-square distribution with one degree of freedom. Rejection is interpreted as indicating that at least one of the instruments is not valid. The results indicate that with the exception of the southern European countries, the instrumental variable based on twin births can be considered a valid instrument for all regions of Europe considered in our analysis (Appendix Table 8).

In addition, we carried out a number of additional analyses in order to check the sensitivity of our results with respect to modifications of the sample according to ethnicity, age, partnership status, and age at first birth. Specifically, we examined the effects of family size on labor market outcomes of women in the sample (1) restricted to women of EU origin, (2) extended to women up to age 45, (3) restricted to partnered (married or cohabiting) women, and (4) restricted to women who had their first birth before age 30 .

The findings from these analyses are available on request. They demonstrate that our conclusion that the number of children does not have a negative effect in the Nordic and the CEE countries is robust across all of the samples except for two cases: the sample of women of EU origin in the Nordic countries, among whom the estimate of the negative effect of the number of children on the probability of working (but not the number of working hours) becomes significantly (but marginally) positive; and the sample of partnered women in the CEE countries, among whom the estimate of the negative effect of the number of children on the probability of working (but not the number of working hours) becomes significantly (although marginally) negative. However, the magnitude of the effect in the latter sample remains smaller than in the other western and southern European countries, where it was found to be negative as well.

Table 6 Test of validity of twinbased instrument in regression of female employment on family size

Source: EU-SILC data 2004-2011

\begin{tabular}{lll}
\hline & $\begin{array}{l}p \text {-value from Brausch- } \\
\text { Pagan test of } \\
\text { heteroskedasticity }\end{array}$ & $\begin{array}{l}p \text {-value from Sargan } \\
\text { test of exogeneity } \\
\text { of twin IV }\end{array}$ \\
\hline Nordic & 0.0000 & 0.1569 \\
Western-French & 0.0000 & 0.1114 \\
Other Western & 0.0000 & 0.3602 \\
Anglosaxon & 0.0192 & 0.1956 \\
Southern & 0.0000 & 0.0108 \\
CEE & 0.0000 & 0.4697 \\
\hline
\end{tabular}


Table 7 Test of validity of twinbased instrument in regression of female hours of work on family size

Source: EU-SILC data 2004-2011

\begin{tabular}{lll}
\hline & $\begin{array}{l}p \text {-value from Brausch- } \\
\text { Pagan test of } \\
\text { heteroskedasticity }\end{array}$ & $\begin{array}{l}p \text {-value from Sargan } \\
\text { test of exogeneity } \\
\text { of twin IV }\end{array}$ \\
\hline Nordic & 0.0000 & 0.0770 \\
Western-French & 0.0001 & 0.0920 \\
Other Western & 0.0000 & 0.5804 \\
Anglosaxon & 0.0000 & 0.6651 \\
Southern & 0.0000 & 0.0111 \\
CEE & 0.0000 & 0.1533 \\
\hline
\end{tabular}

\section{Discussion of Key Findings}

The aim of this paper was to investigate how the conditions for work and family reconciliation influence the effects of family size on women's employment. Contrary to most of the previous research on the topic, we were able to account for the selection of family-oriented women into the pool of mothers. This was achieved by estimating instrumental variable models using data on multiple births based on the cross-country comparative data for Europe. Our findings clearly show that family size has negative effects on the probability of working and on the number of working hours among women in all of the country groups, except in the Nordic and the CEE countries, where the effects were found to be insignificant. The negative effects emerged regardless of whether we controlled for selection, but they were much weaker after controls were applied. This suggests that previous research that did not take selection into account likely overestimated the negative effect of family size on women's employment. The negative effects of family size on women's employment are fairly strong in two country groups, the Anglo-Saxon countries (Ireland and the United Kingdom) and southern Europe (Italy, Greece, Portugal, and Spain), where public support for working parents is indeed weak and where families have to largely rely on either the market (AngloSaxon countries) or the family (southern Europe) to combine paid work with childrearing. These effects seem to be somewhat weaker, but still significantly negative, in the western French-speaking countries (France and Belgium) and in the other western countries (Austria, Germany, the Netherlands, and Luxembourg), even though the public support for working mothers in France and Belgium is better than in the remaining western European countries.

No significantly negative effects of family size on women's employment were found in the Nordic and the post-socialist countries. The finding for the Nordic countries is most likely due to a consistent set of policies in the Nordic states designed to support gender equality in the labor market as well as at home. This policy framework, which has been in place for at least three decades (Leira 2002), includes the broad provision of high quality childcare services to all social strata, and a system of individualized parental leaves that encourages an equal division of care of very young children between the partners. The Nordic countries are currently considered to have the most egalitarian division of paid and unpaid labor (Goldscheider et al. 2015) and to have the best conditions for work and family reconciliation (Matysiak and Weziak-Bialowolska 2016).

In the post-socialist countries, the conditions for work and family reconciliation are far worse than in the Nordic countries. In many of those countries childcare provision for the youngest children (under age 3 ) is even worse than in many western European countries 
and men's levels of involvement in unpaid labor at home are relatively low (Fisher and Robinson 2011). Instead, women are offered extensive parental leave opportunities to provide care at home (Saxonberg and Sirovátka 2006; Robila 2012). Nonetheless, in our study we found that raising children does not affect women's employment in this part of Europe in general and has an only slightly negative effect on the probability of working among partnered women. These findings are consistent with those of previous research on CEE countries. Using different methods and different data, this research showed that in this region, women's employment is affected by family size to a lesser extent than in other European countries (except in the Nordic countries) (Matysiak and Steinmetz 2008; Matysiak and Vignoli 2008) and that working women are less likely to postpone the transition to motherhood than women in other European countries (Kreyenfeld 2004; Róbert and Bukodi 2005). Financial necessities and cultural factors (the intergenerational transmission of the image of the working mother) are most often referenced in explanations for these empirical findings. On the one hand, women in the post-socialist countries are expected by society to care for their children at home (Treas and Widmer 2000; Muszyńska 2007). Given the poor childcare provision and generous parental leave programs, women in these countries have few options other than to combine paid work and care. On the other hand, however, women are supposed to accept a double burden once their children are older, and to work for pay just as their mothers did under socialism in order to contribute to the tight household budget (Lück and Hofäcker 2003; Philipov 2008). A desire to contribute to their family's finances and to improve their family's living standards are often mentioned in empirical studies for the region when young parents are asked why they are willing to accept long working hours and strong work pressures, and why they reject the idea of advocating for shorter or more flexible working hours to achieve greater work-family balance (Hobson et al. 2011; Mrcela and Sadar 2011). Thus, the common pattern found in the data is that women in the CEE countries tend to take long career breaks after the birth of a child (even up to three years), thereby taking advantage of the relatively generous parental leave schemes; and then return to employment, often full-time (Matysiak 2011b).

In this study we focused on the effects of the number of children on female employment and we did not elaborate on other kinds of consequences of motherhood. An issue that definitely requires more attention in future research is the impact of the number of children on women's wages. In some countries, notably in the Nordic countries, gender equality in terms of employment chances coincides with a high degree of gender segregation across public and private sectors, and is accompanied by clear differences in wages across these sectors (Hansen 1997). Hence, while this study documents the differences in the effect of family size on the female labor supply in countries with different welfare state regimes, there may be still be trade-offs between employability and financial rewards for work among mothers in different countries.

While this study focuses on the impact of the number of children on female employment across groups of countries, the differences in the institutional and the cultural settings of these countries might also affect national fertility levels (Thévenon and Gauthier 2011). These differences may be important when considering the aging of European societies, and the challenges associated with this process for socioeconomic development. Hence, the positive impact of family-friendly institutional arrangements may have effects not only on current employment rates, but also on generational relations in Europe over the long term. Documenting such long-term influences goes beyond the scope of this article, and is left for future research. 
Acknowledgments This research was carried out within a project The impact of the number of children on the well-being of families in Europe financed by the grant no DEC-2011/03/D/HS4/04258 from the National Science Centre in Poland. The authors have benefited from the comments and suggestions received from the participants of meetings of the Population Association of America in New Orleans in 2013, the Research Committee on Social Stratification and Mobility of the International Sociological Association in Trento in May 2013, and the European Consortium for Sociological Research "Developments in Social Inequality and Social Cohesion" in September 2014 in Tilburg. We would also like to thank the editor and an anonymous reviewer for their constructive criticisms and helpful comments on an earlier draft of this paper.

\section{Compliance with Ethical Standards}

Conflict of Interest The authors declare that they have no conflict of interest.

Open Access This article is distributed under the terms of the Creative Commons Attribution 4.0 International License (http://creativecommons.org/licenses/by/4.0/), which permits unrestricted use, distribution, and reproduction in any medium, provided you give appropriate credit to the original author(s) and the source, provide a link to the Creative Commons license, and indicate if changes were made.

\section{Appendix}

Table 8 Sample distribution according to the group of countries

\begin{tabular}{llll}
\hline & $\begin{array}{l}\text { mothers with } \\
\text { twins at 1st birth }\end{array}$ & other mothers & total \\
\hline Nordic & 129 & 10,714 & 10,843 \\
Western-French & 249 & 18,457 & 18,706 \\
Other Western & 287 & 20,893 & 21,180 \\
Anglosaxon & 114 & 7334 & 7448 \\
Southern & 389 & 25,246 & 25,635 \\
CEE & 551 & 50,977 & 51,528 \\
Total & 1719 & 133,621 & 135,340 \\
\hline
\end{tabular}

Source: EU-SILC data, 2004-2011

Table 9 Associations between socio-demographic characteristics and the probability of a twin birth at first birth

Source: EU-SILC data. Fixed ef-

\begin{tabular}{lll}
\hline & Coef. & S.E. \\
\hline Age & $-0.000^{* * *}$ & $(0.000)$ \\
Age at 1st birth & $0.002^{* * *}$ & $(0.000)$ \\
Education attainment (ref. no primary) & \\
$\quad$ primary & 0.001 & $(0.002)$ \\
lower secondary & 0.001 & $(0.001)$ \\
$\quad$ upper secondary & -0.000 & $(0.002)$ \\
$\quad$ tertiary & -0.002 & $(0.002)$ \\
$\quad$ missing education & -0.001 & $(0.004)$ \\
Missing quarter of birth & $0.002^{*}$ & $(0.001)$ \\
Non-EU origin & $0.003^{* *}$ & $(0.001)$ \\
constant & $-0.019^{* * *}$ & $(0.003)$ \\
$\mathrm{N}$ & 135,340 & \\
\hline
\end{tabular}




\section{References}

Aassve A, Burgess S, Propper C, Dickson M (2006) Employment, family union and childbearing decisions in Great Britain. Journal of the Royal Statistical Society: Series A (Statistics in Society) 169(4):781-804. doi:10.1111/j.1467-985X.2006.00432.x

Adsera A (2005) Vanishing children: from high unemployment to low fertility in developed countries. Am Econ Rev 95(2):189-193. doi:10.1257/000282805774669763

Agüero JM, Marks MS (2008) Motherhood and female labor force participation: evidence from infertility shocks. Am Econ Rev 98(2):500-504. doi:10.1257/aer.98.2.500

Agüero JM, Marks MS (2011) Motherhood and female labor supply in the developing world: evidence from infertility shocks. J Hum Resour. doi:10.1353/jhr.2011.0002

Ahn N, Mira P (2002) A note on the changing relationship between fertility and female employment rates in developed countries. J Popul Econ 15(4):667-682. doi:10.1007/s001480100078

Angrist JD, Evans WN (1998) Children and their parents' labor supply: evidence from exogenous variation in family size. Am Econ Rev 88(3):450-477

Angrist J, Imbens G, Rubin D (1996) Identification of causal effects using instrumental variables. J Am Stat Assoc 91(434):444-455. doi:10.1080/01621459.1996.10476902

Angrist J, Lavy V, Schlosser A (2010) Multiple experiments for the causal link between the quantity and quality of children. J Labor Econ 28(4):773-824. doi:10.1086/653830

Anttonen A, Sipilä J (1996) European social care services: is it possible to identify models? Journal of European Social Policy. doi:10.1177/095892879600600201

Arpino B, Aassve A (2013) Estimating the causal effect of fertility on economic wellbeing: data requirements, identifying assumptions and estimation methods. Empir Econ 44(1):355-385. doi:10.1007/s00181-010-0356-9

Bettio F, Plantenga J (2004) Comparing care regimes in Europe. Fem Econ. doi:10.1080/ 1354570042000198245

Blau FD, Kahn LM (2007) Changes in the labor supply behavior of married women: 1980-2000. J Labor Econ. doi:10.1086/513416

Bray JW (2005) Alcohol use, human capital, and wages. J Labor Econ. doi:10.1086/428025

Brewster KL, Rindfuss RR (2000) Fertility and women's employment in industrialized nations. Annu Rev Sociol. doi:10.1146/annurev.soc.26.1.271

Budig MJ (2003) Are women's employment and fertility histories interdependent? An examination of causal order using event history analysis. Soc Sci Res. doi:10.1016/S0049-089X(03)00012-7

Cáceres-Delpiano J (2012) Can we still learn something from the relationship between fertility and mother's employment? Evidence from developing countries. Demography. doi:10.1007/s13524-011-0076-6

Cristia JP (2008) The effect of a first child on female labor supply evidence from women seeking fertility services. J Hum Resour. doi:10.3368/jhr.43.3.487

Cruces G, Galiani S (2007) Fertility and female labor supply in Latin America: new causal evidence. Labor Economics. doi:10.1016/j.labeco.2005.10.006

Daouli J, Demoussis M, Giannakopoulos N (2009) Sibling-sex composition and its effects on fertility and labor supply of Greek mothers. Econ Lett. doi:10.1016/j.econlet.2009.01.002

Del Boca D, Sauer RM (2009) Life cycle employment and fertility across institutional environments. Eur Econ Rev. doi:10.1016/j.euroecorev.2008.06.001

Del Boca D, Pasqua S, Pronzato C (2009) Motherhood and market work decisions in institutional context: a European perspective. Oxf Econ Pap. doi:10.1093/oep/gpn046

Drobnič S (1997) Part-time work in central and eastern European countries. In: Blossfeld H-P, Hakim C (eds) Between equalization and marginalization women working part-time in Europe and the United States of America. Oxford University Press, Oxford, pp 71-89

Engelhardt H, Kögel T, Prskawetz A (2004) Fertility and women's employment reconsidered: a macro-level time-series analysis for developed countries, 1960-2000. Popul Stud. doi:10.1080/ 0032472032000167715

Esping-Andersen G (1999) Social foundations of postindustrial economies. Oxford University Press, Oxford

European Commission (2015) Maternity, paternity and parental leave: data related to duration and compensation rates in the European Union. Directorate General for Internal Policies. Policy Department C: Citizens' Rights and Constitutional Affairs

Eurostat (2011) European Union Statistics on Income and Living Conditions (EU-SILC), cross-sectional files, 2004-2011

EVS (2016). European Values Study 2008: Integrated dataset (EVS 2008). GESIS data archive, Cologne. ZA4800 Data file Version 4.0.0, doi:10.4232/1.12458 
Felmlee DH (1993) The dynamic interdependence of women's employment and fertility. Soc Sci Res. doi:10. 1006/ssre.1993.1017

Fisher K, Robinson J (2011) Daily life in 23 countries. Soc Indic Res. doi:10.1007/s11205-010-9650-3

Francesconi M (2002) A joint dynamic model of fertility and work of married women. J Labor Econ. doi:10. $1086 / 338220$

Giannelli GC (1996) Women's transitions in the labour market: a competing risks analysis on German panel data. J Popul Econ 9(3):287-300

Goldscheider F, Bernhardt E, Lappegård T (2015) The gender revolution: a framework for understanding changing family and demographic behavior. Popul Dev Rev. doi:10.1111/j.1728-4457.2015.00045.x

Gornick JC, Meyers MK, Ross KE (1997) Supporting the employment of mothers: policy variation across fourteen welfare states. J Eur Soc Policy 7(1):45-70

Habbema J.D.F., Collins J., Leridon H., Evers J., Lunenfeld B.\& Velde E.R. (2004) Towards less confusing terminology in reproductive medicine: a proposal. Human Reproduction. doi:10.1093/humrep/deh303

Hakim C (2003) A new approach to explaining fertility patterns: preference theory. Popul Dev Rev 29(3):349374

Hansen MN (1997) The Scandinavian welfare state model: the impact of the public sector on segregation and gender equality. Work, Employment \& Society. doi:10.1177/0950017097111005

Hobson B, Fahlen S, Takacs J (2011) Agency and capabilities to achieve a work-life balance: a comparison of Sweden and Hungary. Social Politics. doi:10.1093/sp/jxr007

Hotz VJ, Mullin C, Sanders S (1997) Bounding causal effects using data from a contaminated natural experiment: analysing the effects of teenage childbearing. Rev Econ Stud 64(4):575-603

Hotz VJ, McElroy SW, Anders SG (2005) Teenage childbearing and its life cycle consequences: exploiting a natural experiment. J Hum Resour 40(3):683-715

Jacobsen JP, Pearce JW III, Rosenbloom JL (1999) The effects of childbearing on married women's labor supply and earnings: using twin births as a natural experiment. J Hum Resour 34(3):449-474. doi:10. 2307/146376

Joesch JM (1994) Children and the timing of women's paid work after childbirth: a further specification of the relationship. J Marriage Fam 56(2):429-440

Johansson E, Alho H, Kiiskinen U, Poikolainen K (2007) The association of alcohol dependency with employment probability: evidence from the population survey 'Health 2000 in Finland'. Health Econ. doi:10.1002/hec. 1201

Joshi H (1998) The opportunity costs of childbearing: more than mothers' business. J Popul Econ 11(2):161183

Kelly IR, Dave DM, Sindelar JL, Gallo WT (2014) The impact of early occupational choice on health behaviors. Rev Econ Househ. doi:10.1007/s11150-012-9166-5

Kline J, Stein Z, Shrout P, Susser M, Warburton D (1980) Drinking during pregnancy and spontaneous abortion. Lancet. doi:10.1016/S0140-6736(80)90062-8

Korpi W (2000) Faces of inequality: gender, class, and patterns of inequalities in different types of welfare states. Social Politics: International Studies in Gender, State \& Society 7(2):127-191

Kreyenfeld F (2004) Fertility decisions in the FRG and GDR: an analysis with data from the German fertility and family survey. Demographic Research. doi:10.4054/DemRes.2004.S3.11

Lehrer E, Nerlove M (1986) Female labor force behavior and fertility in the United States. Annu Rev Sociol. doi:10.1146/annurev.so.12.080186.001145

Leira A (2002) Working parents and the welfare state. Family change and policy reform in Scandinavia. Cambridge University Press, Cambridge

Levine PB, Gustafson TA, Velenchik AD (1997) More bad news for smokers? The effects of cigarette smoking on wages. Ind Labor Relat Rev. doi:10.1177/001979399705000307

Lewbel A (2012) Using heteroscedasticity to identify and estimate mismeasured and endogenous regressor models. J Bus Econ Stat. doi:10.1080/07350015.2012.643126

Lück D, Hofäcker D (2003) Rejection and acceptance of the male breadwinner model: which preferences do women have under which circumstances? Globalife Working Paper 60

Luke B, Martin JA (2004) The rise in multiple births in the United States: who, what, when, where, and why. Clin Obstet Gynecol 47(1):118-133

Martin JA, Park MM (1999) Trends in twin and triplet births: 1980-97. National Vital Statistics Report 47:1-16

Matysiak A. (2011a) Interdependencies between fertility and women's labour supply. Springer, Netherlands

Matysiak A (2011b) Fertility developments in Central and Eastern Europe: the role of work-family tensions. Demográfia 54(5):7-30 
Matysiak A, Steinmetz S (2008) Finding their way? Female employment patterns in West Germany, East Germany, and Poland. Eur Sociol Rev 24:331-345. doi:10.1093/esr/jcn007

Matysiak A, Vignoli D (2008) Fertility and women's employment: a meta-analysis. Eur J Popul 24(4): 363384

Matysiak A, Weziak-Bialowolska D (2016) Country-specific conditions for work and family reconciliation: an attempt at quantification. European Journal of Population (Online first)

Mincer J, Ofek H (1982) Interrupted work careers: depreciation and restoration of human capital. J Hum Resour. doi: $10.2307 / 145520$

Moffitt R (2005) Remarks on the analysis of causal relationships in population research. Demography. doi:10. 1353/dem.2005.0006

Mrcela AK, Sadar NC (2011) Social policies related to parenthood and capabilities of Slovenian parents. International Studies in Gender, State \& Society, Social Politics. doi:10.1093/sp/jxr010

Muszyńska M (2007) Structural and cultural determinants of fertility in Europe. Warsaw School of Economics, Warsaw

Nam K (2010) The effect of having more children on women's labour force participation in Korea: an analysis using instrument variables. Labour 24(3):333-356

Nieuwenhuis R, Need A, Van Der Kolk H (2012) Institutional and demographic explanations of women's employment in 18 OECD countries, 1975-1999. J Marriage Fam. doi:10.1111/j.1741-3737.2012.00965.x

Pascall G, Manning N (2000) Gender and social policy: comparing welfare states in central and Eastern Europe and the former Soviet Union. Journal of European Social Policy 10:240-266

Pettit B, Hook J (2005) The structure of women's employment in comparative perspective. Social Forces. doi: 10.1353/sof.2006.0029

Philipov D (2008) Family-related gender attitudes. In: Hoehn C, Avramov D, Kotowska IE (eds) People, population change and policies. Springer, Heidelberg

Róbert P, Bukodi E (2005) The effects of the globalization process on the transition to adulthood in Hungary. In: Blossfeld H-P, Klijzing E, Mills M, Kurz K (eds) Globalization. Routledge, Uncertainty and Youth in Society. London and New York, pp. 176-214

Robila M (2012) Family policies in Eastern Europe: a focus on parental leave. J Child Fam Stud 21(1):32-41

Rønsen M, Sundström M (2002) Family policy and after-birth employment among new mothers - a comparison of Finland. Norway and Sweden European Journal of Population. doi:10.1023/ A:1015532305179

Rosenzweig MR, Wolpin KI (1980) Life-cycle labor supply and fertility: causal inferences from household models. J Polit Econ 328-348

Rosenzweig MR, Wolpin KI (2000) Natural 'natural experiments' in economics. J Econ Lit. doi:10. $1257 /$ jel.38.4.827

Rosenzweig MR, Zhang J (2009) Do population control policies induce more human capital investment? Twins, birth weight and China's “one-child” policy. Review of Economic Studies. doi:10.1111/j.1467937X.2009.00563.x

Sabia JJ (2007) Early adolescent sex and diminished school attachment: selection or spillovers? South Econ J. doi: $10.2307 / 20111933$

Saxonberg S, Sirovátka T (2006) Failing family policy in post-communist Central Europe. Journal of Comparative Policy Analysis. doi:10.1080/13876980600682089

Sobotka T (2004) Is lowest-low fertility in Europe explained by the postponement of childbearing? Popul Dev Rev. doi:10.1111/j.1728-4457.2004.010_1.x

Staiger D, Stock JH (1997) Instrumental variables regression with weak instruments. Econometrica. doi:10. $2307 / 2171753$

Steiber N, Haas B (2012) Advances in explaining women's employment patterns. Socioeconomic Review. doi:10.1093/ser/mwr039

Steiner V, Wrohlich K (2004) Household taxation, income splitting and labor supply incentives - a microsimulation study for Germany. CESifo Economic Studies 50(3):541-568

Stier H, Lewin-Epstein N, Braun M (2001) Welfare regimes, family-supportive policies, and women's employment along the life-course. Am J Sociol. doi:10.1086/321302

Szelewa D, Polakowski MP (2008) Who cares? Changing patterns of childcare in Central and Eastern Europe. J Eur Soc Policy. doi:10.1177/0958928707087589

Taniguchi H, Rosenfeld RA (2002) Women's employment exit and reentry: differences among Whites, Blacks, and Hispanics. Soc Sci Res. doi:10.1016/S0049-089X(02)00009-1

Thévenon O, Gauthier AH (2011).Family policies in developed countries: A 'fertility-booster'with side effects. Community, Work \& Family 14(2):197-216 
Treas J, Widmer ED (2000) Married women's employment over the life course: attitudes in cross-national perspective. Soc Forces. doi:10.1093/sf/78.4.1409

Uunk W, Kalmijn M, Muffels R (2005) The impact of young children on women's labour supply: a reassessment of institutional effects in Europe. Acta Sociologica. doi:10.1177/0001699305050986

Vere JP (2011) Fertility and parents' labour supply: new evidence from US census data. Oxf Econ Pap. doi:10. 1093/oep/gpr003

Wooldridge JM (2010) Econometric analysis of cross section and panel data. MIT Press, Cambridge 